\title{
Hubungan Amplitudo Gelombang Fibrilasi dengan Irama kembali ke Sinus pada Pasien Non Valvular Recent Onset Atrial Fibrillation
}

\author{
Chandra Wijaya, ${ }^{1 *} \operatorname{Irwan}^{1}$
}

\begin{abstract}
Atrial fibrillation (AF) is a strong risk factor for death with an increase from 1.5 to 1.9 times in the analysis of Framingham. A Fis also associated with an increase of 5 times the incidence of stroke. Many studies have attempted to search for any parameters that can predict whether the AFin patients with recent-onset FA can still return to sinus rhythm mornot, but the results still un satisfactory. This is a descriptive analytic study. The subjects were all patients with recent onset atrial fibrillation ( $<72$ hours). Analysis test conducted by test unpaired T-test for numerical variables and chi-square test for categorical variables. From 68 subjects there were 36 patients $(52.9 \%)$ with return to sinus. After analysis showed that Coarse $\mathrm{AF}(95 \% \mathrm{CI} 0.11$ to $0.82, \mathrm{P}=0.017)$ have significant relationship return to sinus in patients with recent onset atrial fibrillation.
\end{abstract}

Keyword: Recent onset AF, Coarse AF, Fine AF

Fibrilasi atrium (FA) merupakan aritmia yang paling sering ditemui dalam praktek sehari-hari, dengan prevalensi mencapai 1-2\% dan akan semakin meningkat dengan bertambahnya usia. ${ }^{1,2}$ Menurut data WHO untuk Indonesia pada tahun 2000-2005 terjadi peningkatan signifikan persentase populasi usia lanjut yaitu 7,74\% dan diperkirakan pada tahun 2045-2050 akan meningkat menjadi 28,68\%, seiring dengan ini maka kejadian fibrilasi atrium juga akan meningkat secara signifikan. Data Rumah Sakit Jantung dan Pembuluh Darah Harapan Kita menunjukan persentase kejadian FA pada pasien rawat selalu meningkat setiap tahunnya, yaitu $7,1 \%$ pada tahun 2010, meningkat menjadi 9\% (2011), 9,3\% (2012), dan 9,8\% (2013). ${ }^{1} \mathrm{FA}$ adalah faktor risiko kuat untuk kematian dengan peningkatan 1,51,9 kali dalam analisis Framingham. FA juga dihubungkan dengan peningkatan 5 kali kejadian stroke dan faktor penyebab dari 5\% kejadian emboli di serebral. Studi terbaru menemukan adanya 10$30 \%$ FA pada pasien gagal jantung yang simtomatik, dengan peningkatan kematian $34 \%$ bila dibandingkan dengan gagal jantung saja. ${ }^{2}$

\footnotetext{
* Korespondensi: cdrwjy@ gmail.com

1 KJF Jantung dan Kedokteran Vaskuler, Fakultas Kedokteran Universitas Riau
}

Pengembalian irama ke sinus mempunyai kelebihan mengurangi risiko tromboemboli, memperbaiki hemodinamik dengan mengembalikan 'atrial kick', mencegah terjadinya respon ventrikel cepat yang dapat menginduksi kardiomiopati akibat takikardia, serta mencegah remodelling atrium yang dapat meningkatkan ukuran atrium dan menyebabkan kardiomiopati atrium. ${ }^{2}$ Beberapa penelitian memperlihatkan pasien FA recent onset yaitu onset $<48$ jam, bahkan pada penelitian lain disebutkan $<72$ jam memperlihatkan hasil bahwa irama FA dapat kembali menjadi sinus dalam periode 24 jam. Ini juga didukung dengan penelitian yang menunjukkan bahwa semakin pendek durasi kejadian FA maka dapat memprediksi irama FA dapat kembali ke sinus. ${ }^{3,4}$ Apakah amplitudo gelombang fibrilasi juga mempengaruhi irama fibrilasi atrial dapat kembali ke irama sinus atau tidak sudah ada diteliti, namun menunjukkan hasil yang masih berbeda-beda.Untuk itulah penelitian ini masih perlu dilakukan.

Fibrilasi atrium adalah takikardia supraventrikular dengan karakteristik aktivasi atrium yang tidak terkoordinasi. Fibrilasi atrium mempunyai karakteristik gambaran EKG berupa pola interval RR yang tidak teratur dan tidak ada gambaran gelombang $\mathrm{P}$ yang jelas. ${ }^{1}$ 
Ada beberapa sistem klasifikasi FA yang telah dikemukakan antara lain berdasarkan rekaman EKG permukaan, maka FA dapat dikelompokkan menjadi FA kasar (coarse $A F$ ) dan FA halus (fine $A F$ ). FA kasar menunjukkan FA belum berlangsung lama dan peluang untuk mengkonversi menjadi irama sinus lebih besar dibandingkan dengan FA halus. ${ }^{5}$ Berdasarkan laju respon ventrikel, FA dibagi menjadi FA respon cepat (rapid respon, dimana laju ventrikel $>100$ kali per menit), FA respon lambat (slow response, laju ventrikel $<60$ kali per menit), dan FA respon normal (normo response, laju ventrikel 60-100 kali permenit). Berdasarkan keadaan hemodinamik pada saat FA muncul, maka FA diklasifikasikan menjadi FA dengan hemodinamik stabil dan tidak stabil (hipotensi, gagal jantung, angina atau infark miokard akut). Kelompok FA dengan hemodinamik tidak stabil memerlukan tindakan kardioversi elektrik. ${ }^{6}$

Berdasarkan presentasi dan durasi kejadian FA, maka FA diklasifikasikan menjadi 5 tipe, yaitu: 1 . Fibrilasi atrium yang pertama kali terdiagnosis (First diagnosed $F A$ ), setiap pasien yang baru pertama kali terdiagnosis dengan FA tanpa melihat durasi atau beratnya gejala yang ditimbulkan oleh FA tersebut. 2 . Paroksismal FA, FA yang biasanya hilang dengan sendirinya dalam 48 jam sampai 7 hari. Jika dalam 48 jam belum berubah ke irama sinus maka kemungkinan kecil untuk dapat berubah ke irama sinus lagi sehingga perlu dipertimbangkan pemberian antikoagulan. 3 . Persisten FA, episode FA yang bertahan sampai lebih dari 7 hari dan membutuhkan kardioversi untuk terminasi dengan obat atau dengan elektrik. 4. FA persisten lama (Long standing persistent), episode FA yang berlangsung lebih dari 1 tahun dan strategi yang diterapkan masih kontrol irama jantung (rhythm control). 5. Permanen FA, jika FA menetap dan secara klinis dapat diterima oleh pasien dan dokter sehingga strategi managemen adalah tatalaksana kontrol laju jantung (rate control). ${ }^{4}$

Pengelompokan lain yang juga dipakai adalah penggolongan sebagai FA sekunder yaitu FA yang terjadi akibat kondisi primer yang menjadi pemicu FA, seperti infark miokard akut, perikarditis, paska bedah jantung, hipertiroidisme, dan kelaianan paru. Pada keadaan ini, koreksi terhadap faktor primer akan berpeluang besar menghilangkan FA. ${ }^{7}$

Terminologi lone FA dikhususkan pada penderita yang berusia kurang dari 60 tahun tanpa bukti klinis atau ekokardiografi adanya kelainan sistem jantung paru, termasuk hipertensi. Penyebabnya diduga oleh adanya daerah fibrosis di atrium yang mebuat daerah tersebut rentan terhadap aritmia, lebih sensitif terhadap stimulus autonom dan adanya miokarditis setempat. Istilah nonvalvular FA merujuk pada FA tanpa kelainan katup mitral (terutama mitral stenosis) akibat penyakit jantung reumatik, tidak dalam pemakaian katup prostetik, tidak pernah melakukan operasi perbaikan (repair) katup jantung. ${ }^{4,7}$

Sampai saat ini patofisiologi terjadinya FA masih belum sepenuhnya dipahami dan dipercaya bersifat multifaktorial.Terdapat dua konsep teori yang dipakai tentang bagaimana mekanisme FA bisa terjadi, yaitu adanya faktor pemicu dan faktor-faktor yang melanggengkan. Pada pasien FA yang sering kambuh tetapi masih dapat konversi ke sinus, mekanisme utama yang mendasari biasanya karena adanya faktor pemicu FA, sedangkan pada pasien FA yang tidak dapat konversi ke sinus biasanya didominasi adanya faktor-faktor yang melanggengkan. ${ }^{8}$ Beberapa penelitian menunjukkan adanya berbagai perubahan histopatologi pada jaringan atrium pasien yang menderita FA. Substrat ini terbentuk dari proses remodeling yang terjadi di atrium. Beberapa kondisi seperti perubahan degeneratif pada atrium karena bertambahnya usia, proses inflamasi pada jantung, dan berbagai penyakit jantung kronis lain seperti hipertensi, payah jantung, penyakit jantung katup dan aterosklerosis koroner dapat memicu remodelling yang perlahan tetapi progresif di atrium (Gambar1). ${ }^{9}$

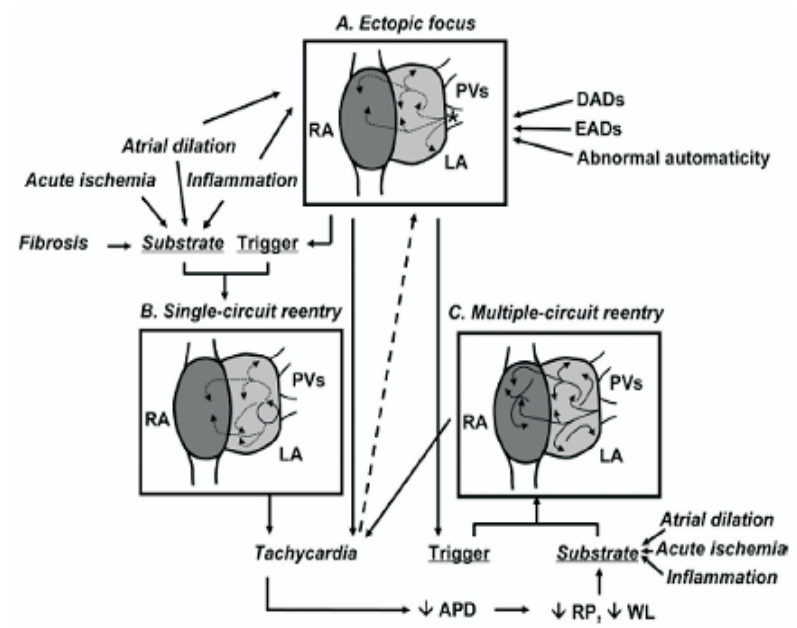

Gambar 1. Mekanisme terbentuknya FA ${ }^{9}$ 
Proses remodelling yang terjadi di atrium mengakibatkan terbentuknya suatu jalur konduksi mempunyai kecepatan konduksi yang lebih lambat dan masa refakter yang lebih pendek dibandingkan yang lain. Kecepatan konduksi menjadi lebih lambat karena proses remodeling menyebabkan pengurangan jumlah kanal ion natrium $\left(\mathrm{I}_{\mathrm{Na}}\right)$, pengurangan kanal gap junctions (gangguan fungsi connexin), proses remodelling juga menyebabkan proliferasi dan diferensiasi fibroblas menjadi miofibroblas yang dapat meningkatkan deposisi jaringan ikat dan fibrosis di atrium. Sedangkan masa refrakter menjadi lebih pendek karena proses remodelling menyebabkan aliran masuk ion $\mathrm{Ca}^{2+}$ berkurang dan aliran keluar ion $\mathrm{K}^{+}$meningkat pada fase plateu dan fase repolarisasi dari potensial aksi

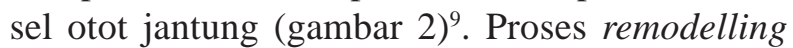
atrium menyebabkan gangguan elektris antara serabut otot dan serabut konduksi di atrium (substrat elektroanatomis).Substrat elektroanatomis ini selanjutnya memfasilitasi terjadinya sirkuit reentri. Pada awalnya hasil dari proses remodelling di atrium yang berupa sustrat elektroanatomis ini akan menghasilkan sirkuit reentritunggal (single-circuit reentry) yang jika ada trigger maka sirkuit ini akan melanggengkan terjadinya FA (gambar 1 dan 2). ${ }^{9}$

Berdasarkan penelitian Allessie dkk menyatakan bahwa fibrilasi atrium kronik dapat menyebabkan proses fibrosis di atrium semakin berlanjut dan terjadi gangguan kontraktilitas atrium yang menyebabkan regangan dan dilatasi atrium. ${ }^{1}$ Hal ini akan menambah terbentuknya substratsubstrat baru (multiple-circuit reentry) sehingga FA yang terjadi semakin sulit untuk dikembalikan ke irama sinus. Apalagi jika faktor lain seperti proses inflamasi, iskemia otot jantung dan penyakit jantung kronis lain juga masih terus berlanjut (gambar1 dan 2). ${ }^{9}$ Konsep ini oleh Allesie dkk disebut dengan konsep FA menyulut FA (AF begets $A F) .{ }^{1}$

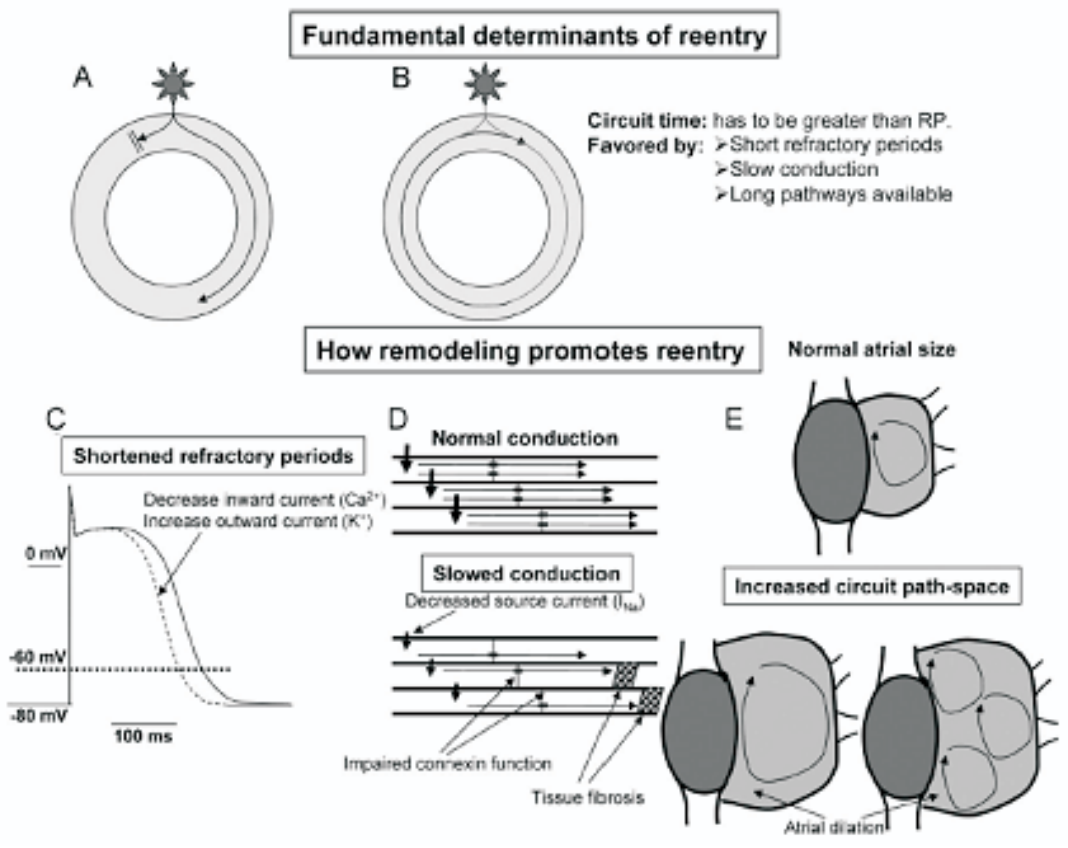

Gambar 2. Proses remodelling merupakan dasar penyebab terbentuknya sirkuit reentri ${ }^{9}$

Awitan dan keberlangsungan takiaritmia membutuhkan adanya pemicu (trigger) dan substrat.Terbentuknya substrat seperti sudah dijelaskan sebelumnya merupakan faktor yang dapat melanggengkan terjadinya FA. Atas dasar itu, mekanisme elektrofisiologis FA dapat dibedakan menjadi mekanisme fokal sebagai pemicu dan mekanisme reentri mikro (multiple wavelet hypothesis) karena adanya substrat. ${ }^{1}$

Mekanisme fokal merupakan faktor yang dapat memicu terjadinya FA yang disebabkan adanya 
aktivitas elektrofisiologis ditempat-tempat tertentu di atrium jantung. Daerah-daerah tersebut antara lain, $72 \%$ di vena pulmonalis dan sisanya $28 \%$ bervariasi dari vena kava superior, dinding posterior atrium kiri, krista terminalis, sinus koronarius, ligamentum Marshall, dan septum interatrium. Mekanisme seluler dari aktivitas fokal mungkin melibatkan mekanisme triggered activity dan otomatisasi abnormal. Vena pulmoner (VP) memiliki potensi yang kuat untuk memulai dan melangggengkan takiaritmia atrium, karena VP memiliki periode refrakter yang lebih pendek. ${ }^{1}$

Pada mekanisme reentri mikro, FA dilanggengkan oleh adanya konduksi beberapa wavelet independen secara kontinyu yang menyebar melalui otot-otot atrium dengan cara yang kacau. Hipotesis ini pertama kali dikemukakan oleh Moe yang menyatakan bahwa FA dilanggengkan oleh banykanya wavelet yang tersebar secara acak dan saling bertabrakan satu sama lain dan kemudian padam, atau berbagi menjadi banyak wavelet lain yang terus-menerus merangsang atrium. Oleh karenanya, sirkuit reentri ini tidak stabil, beberapa menghilang, sedangkan yang lain tumbuh lagi. Sirkuit-sirkuit ini memiliki panjang siklus yang bervariasi tapi pendek. Diperlukan setidaknya 4-6 wavelet mandiri untuk melanggengkan FA. ${ }^{1}$

\section{METODE PENELITIAN}

Penelitian ini merupakan penelitian deskriptif analitik yang mencari hubungan antara amplitudo gelombang fibrilasi dengan kembali irama ke sinus pada pasien non valvular recent onset atrial fibrillation. Variabel bebas pada penelitian ini adalah amplitudo gelombang fibrilasi, sedangkan variabel terikat (dependen) pada penelitian ini merupakan variabel kategori apakah irama FA kembali ke sinus atau tidak.

Saat pasien yang didiagnosis dengan Non valvular recent onset Atrial Fibrillation (onset < 72 jam) dirawat, maka diambil data untuk karakteristik dasar pasien berupa, usia, jenis kelamin, onset keluhan terberat yang menyebabkan pasien ke rumah sakit, apakah ada atau tidak faktor risiko untuk terjadinya FA (seperti hipertensi, CAD, dan lain-lain), pemeriksaan chest $x$-ray, dan golongan obat yang diberikan saat masuk (amiodarone, digoksin, betabloker, dan penghambat kanal kalsium).Sedangkan data-data yang diperlukan untuk dilakukan uji analisis berupa amplitudo gelombang fibrilasi.

Hasil penelitian akan dinyatakan dalam persentase dan mean $\pm S D$. Uji analisis univariat dilakukandengan uji t-test tidak berpasangan untuk variabel numerik dan uji Chi-Square untuk variabel kategorik, hal ini untuk mengetahui apakah amplitudo gelombang fibrillasi secara bermakna mempengaruhi irama FA dapat kembali ke sinus. Seluruh data akan diolah dengan program SPSS for windows versi 18 .

\section{HASIL DAN PEMBAHASAN}

Pada penelitian ini didapatkan 73 pasien dengan Recent onset Atrial Fibrillation. Dari sejumlah pasien tersebut hanya terdapat 68 pasien yang bisa diikutsertakan dalam penelitian ini.Karakteristik dasar subjek penelitian ini terlihat padatabel1. Dari 68 pasien yang dianalisis, rata-rata usia adalah 60 tahun, dengan proporsi laki-laki lebih banyak daripada perempuan.Penyakit dasar yang banyak diderita oleh pasien antara lain hipertensi dan penyakit jantung iskemik. Parameter klinis lain yang paling banyak ditemukan pada pasien yaitu CTR rata-rata $63 \%$, onset keluhan saat datang berobat paling banyak < 24 jam.Berdasarkan karakteristik elektrokardiografi yang paling banyak ditemukan pada penelitian ini adalah jenis FA kasar. Pengobatan awal yang diberikan pada pasien tidak terlalu banyak perbedaan persentasenya yaitu antara amiodaron, beta bloker dan digoksin.Pada gambar 3 , terlihat bahwa dibandingkan dengan beberapa faktor risiko, maka pasien dengan faktor risiko hipertensi mempunyai kemungkinan yang lebih tinggi untuk irama kembali ke sinus. 
Tabel 1. Karaktersitik dasar subyek penelitian

\begin{tabular}{lc}
\hline & $\begin{array}{c}\text { Subjek Penelitian } \\
(\mathbf{n}=\mathbf{6 8})\end{array}$ \\
\hline Usia, tahun (mean \pm SD) & $60,25 \pm 13,15$ \\
Jenis Kelamin, Laki-laki (\%) & 57,4 \\
Penyakit dasar & \\
- Hipertensi, (\%) & 54,4 \\
- Penyakit jantung iskemik (\%) & 69,1 \\
- Gagal jantung, (\%) & 41,2 \\
- Diabetes mellitus (\%) & 47,1 \\
- Gangguan Fungsi Ginjal, (\%) & 47,1 \\
Onset keluhan <24 jam (\%) & 64,7 \\
CTR, \% (mean \pm SD) & $63,67 \pm 8,25$ \\
Amplitudo gelombang fibrilasi & \\
Coarse AF, (\%) & 55,9 \\
Initial terapi & \\
Digoksin, (\%) & 22,1 \\
Beta bloker, (\%) & 35,8 \\
Amiodarone, (\%) & 38,2 \\
\hline
\end{tabular}

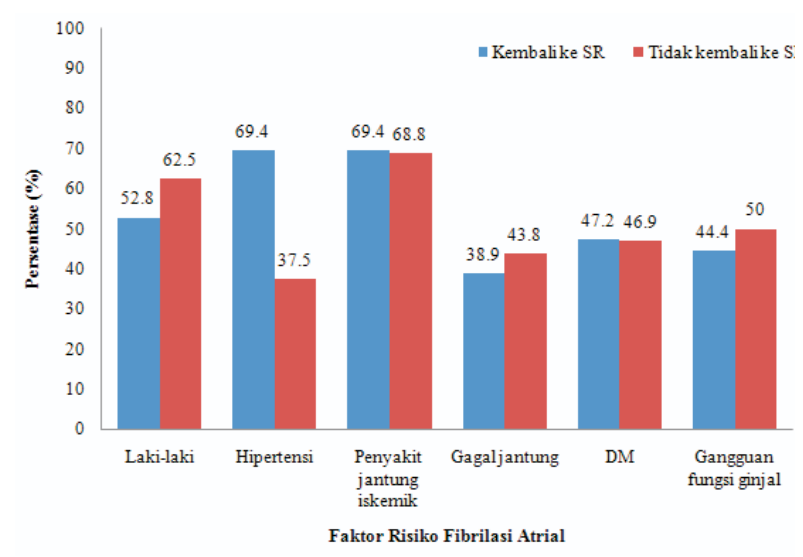

Gambar 3. Persentase irama kembali atau tidak kembali ke sinus berdasarkan faktor risiko fibrilasi atrial

Dari 68 subjek penelitian terdapat 36 pasien $(52,9 \%)$ irama FA dapat kembali ke irama sinus. Setelah dilakukan analisis terhadap variabel bebas yang telah ditentukan sebelumnya, didapatkan bahwa FA kasar berhubungan secara bermakan terhadap kembalinya irama ke sinus( $95 \%$ IK 0,11 $0,82, \mathrm{P}=0,017)$. Dari beberapa literatur menjelaskan bahwa FA kasar lebih mudah kembali ke SR karena adanya beberapa perbedaan antara FA kasar dan halus. ${ }^{6}$ FA kasar mempunyai gelombang fibrilasi antara 150-300 kali/menit dengan fluktuasi amplitudo $\geq 1 \mathrm{~mm}$. Sedangkan FA halus mempunyai gelombang fibrilasi yang lebih cepat (300-650 kali/ menit) dengan fluktuasi amplitudo $<1 \mathrm{~mm} .{ }^{10} \mathrm{FA}$ kasar ditimbulkan karena aktivasi substrat reentrant yang homogen dengan satu atau dua wavelengthyang luas. Ini berbeda dengan FA halus yang ditimbulkan oleh aktivasi substrat reentrant dengan mekanisme atau pola yang lebih komplek dan jumlah wavelength yang lebih banyak dengan ukuran dan terletak di area yang berbeda-beda yang secara simultan teraktivasi sehingga bentuk fluktuasi gelombang fibrilasi sukar dinilai. ${ }^{11}$

Hal ini juga dibuktikan oleh beberapa penelitian sebelumnya seperti yang dilakukan oleh Choudhary dkk, memperlihatkan bahwa frekuensi gelombang fibrillasi yang rendah ( $<350 \mathrm{kali} /$ menit), merupakan faktor independen yang dapat memprediksi irama FA dapat kembali ke irama sinus. ${ }^{3}$ Pada penelitian Bollmann dkk membuktikan bahwa secara klinis FA dengan frekuensi gelombang fibrilasi yang rendah mempunyai respon durasi FA paroksismal yang lebih pendek. ${ }^{12}$ Studi rekaman holter EKG pada 30 pasien dengan FA paroksismal oleh Nilsson F dkk membuktikan bahwa frekuensi gelombang fibrilasi berguna dalam memprediksi 
irama FA kembali ke sinus dengan tingkat akurasi yang tinggi. ${ }^{13}$ Penelitian yang sama oleh Chiarugi dkk juga mendapatkan frekuensi gelombang fibrilasi dan laju jantung merupakan prediktor FA paroksismal dapat kembali ke sinus dengan akurasi 90\%. ${ }^{14}$ Penelitian lain oleh Husser dkk pada 25 pasien dengan onset baru FA mendapatkan bahwa frekuensi gelombang fibrilasi $<355 \mathrm{kali} /$ menit merupakan prediktor kuat irama FA dapat kembali ke sinus dengan sensitivitas $89 \%$ dan spesifisitas $71 \% .^{15}$

\section{KESIMPULAN}

Rata-rata usia subyek penelitian adalah 60 tahun, proporsi lebih banyak pada laki-laki. Penyakit dasar yang banyak diderita oleh pasien adalah hipertensi dan penyakit jantung iskemik. Pasien dengan faktor risiko hipertensi mempunyai persentase lebih besar untuk irama kembali ke sinus. FA kasar merupakan faktor independen kembalinya ke irama sinus pada pasien recent onset fibrilasi atrium.

\section{DAFTAR PUSTAKA}

1. Yuniadi Y, Tondas AE, Hanafy DA, Hermanto DY, Maharani E, Munawar M, dkk. Pedoman tatalaksana fibrilasi atrium. Edisi 1: Centra Communications;2014.

2. Yansen I, Yuniadi Y. Tatalaksana fibrilasi atrium: Kontrol irama atau laju jantung. CDK 2013;40:171-175.

3. Choudhary1 MB, Holmqvist F, Carlson J, Nilsson HJ, Roijer A, Platonov PG. Low atrial fibrillatory rate is associated with spontaneous conversion of recent-onset atrial fibrillation. Europace. 2013;15:1445-1452.

4. Camm AJ, Kirchhof P, Lip GYH, Schotten U, Ernst S, Gelder ICV, et al. Guidelines for the management of atrial fibrillation: The Task force for the management of atrial fibrillation of the European Society of Cardiology (ESC). Eur Heart J. 2010;31:2369-2429.
5. Watson T, Shapstila E, Lip GYH. Management of atrial fibrillation: an overview of the NICE guidance on AF management. BR J Cardiol. 2007; 14:23-28.

6. Phibbs BP. Advanced ECG: boards and beyond. $2^{\text {nd }}$ Ed. USA: Elsevier Saunders;2006.

7. Wakai A, O'Neil JO. Emergency management of atrial fibrillation. Heart. 2003;89:939-943.

8. Falk RB. Atrial fibrillation. N Engl J Med. 2001;344:1067-1076.

9. Page RL, Newly diagnosed atrial fibrillation. $\mathrm{N}$ Engl J Med. 2004;351:2408-2416.

10.King DE, Dickerson PM, Sack JL. Acute management of atrial fibrillation: Part I. rate and rhythm control. Am Fam Physician. 2002;66(2):249-257.

11. Yilmaz MB, Guray Y, Guray U, Cay S, Caldir V, Biyikoglu SF, et al. Fine vs coarse atrial fibrillation: Which one is more risky? Cardiology. 2007;107:193-6.

12.Bollmann A, Sonne K, Esperer HD, Toepffer I, Langberg JJ, Klein HU. Non-invasiveassessment of fibrillatory activity in patients with paroxysmal and persistent atrialfibrillation using the Holter ECG. Cardiovasc Res. 1999;44:60-6.

13.Nilsson F, Stridh M, Bollmann A, Sornmo L. Predicting spontaneous termination of atrial fibrillation using the surface ECG. Med Eng Phys. 2006;28:802-8.

14.Chiarugi F, Varanini M, Cantini F, Conforti F, Vrouchos G. Noninvasive ECG as a tool for predicting termination of paroxysmal atrial fibrillation. IEEE Trans Biomed Eng. 2007;54:1399-406.

15. Husser D, Cannom DS, Bhandari AK, Stridh M, Sornmo L, Olsson SB, et al. Electrocardiographic characteristics of fibrillatory waves in new-onset atrial fibrillation. Europace. 2007;9:638-42. 